\title{
ANÁLISE DO PERFIL E PARTICIPAÇÃO DE ALUNOS DA EDUCAÇÃO A DISTÂNCIA EM UM PROJETO DE INICIAÇÃO CIENTÍFICA
}

\author{
LONDRINA/PR MAIO/2018
}

\author{
Ariane Maria Machado de Oliveira - UNOPAR - ariane.oliveira@kroton.com.br \\ Hallynnee Héllenn Pires Rossetto - UNOPAR - hallynnee.rossetto@kroton.com.br \\ Alexander Luis Montini - UNOPAR - alexander.montini@unopar.br \\ Ivan Ferreira de Campos - UNOPAR - ivan.campos@kroton.com.br \\ Renato José da Silva - UNOPAR - renato.dsilva@kroton.com.br
}

\author{
Tipo: Relato de Experiência Inovadora (EI) \\ Categoria: Pesquisa e Avaliação \\ Setor Educacional: EDUCAÇÃO SUPERIOR
}

\begin{abstract}
RESUMO
Conhecer quem são os estudantes que participam de um Projeto de Iniciação Científica na modalidade de Ensino a Distância é importante para que se possa adotar práticas e priorizar ações para grupos específicos, alcançando maiores níveis de participação. O presente estudo, busca caracterizar do ponto de vista sociodemográfico, os alunos ativos no PIC/Ead intitulado A Educação Financeira utilizada por professores na Educação Básica no Brasil. Foram consideradas informações de 241 alunos ativos no projeto, coletadas no momento da inscrição e por meio da plataforma de iniciação científica da própria Universidade. Os resultados apontaram que a maioria dos alunos são mulheres, e a faixa etária predominante é de 26 a 30 anos. Um dado importante é quanto a distribuição geográfica dos alunos ativos, que estão presentes em todas as regiões brasileiras, demonstrando a importância do projeto que ao final, retratará a realidade brasileira com mais precisão. Com relação a participação dos alunos, nota-se a necessidade do desenvolvimento de algumas ações estratégicas específicas em busca de maior envolvimento dos alunos ativos.
\end{abstract}

Palavras-chave: Iniciação Científica, Educação a Distância, Perfil Sócio-Demográfico 


\section{INTRODUÇÃO}

A evolução das tecnologias de Informação e Comunicação (TIC) em diversos âmbitos tal como em organizações econômicas e em redes sociais, também se manifesta na educação e possibilitou a expansão de novas tecnologias e diversas formas de interação, não somente síncronas, mas também assíncronas. Deste modo, a interação pessoal cede lugar a uma forma de interação chamados de ambientes virtuais de aprendizagem (AVA) desenvolvidos na internet (SILVA, et al., 2015). Como o apoio dos Ambientes Virtuais de Aprendizagem (AVA), plataformas online são desenvolvidas para que o estabelecimento da comunicação entre estudantes e docentes aconteça independentemente da localização onde estes se encontrem. A instituição de ensino ao adotar o (AVA) como ferramenta de ensino digital, proporciona espaço de mediação, interação, participação e colaboração entre estudantes e professores.

Por meio de uma nova plataforma, chamada Ambiente Virtual de Aprendizagem - AVA Stricto, a Universidade Pitágoras UNOPAR tem desenvolvido diversos projetos de iniciação científica junto aos alunos da Educação a Distância. Um deles é o projeto intitulado A Educação Financeira utilizada por professores na Educação Básica no Brasil, que busca analisar se a educação financeira tem sido abordada na educação básica das escolas brasileiras, e de que forma vem ocorrendo.

O projeto conta atualmente com 241 alunos ativos, 8 docentes e 5 coordenadores dos cursos envolvidos. Neste processo inicial de implementação do projeto, notou-se uma baixa participação dos alunos quanto a realização das atividades. Neste sentido, o presente artigo tem como objetivo analisar o perfil e a participação dos alunos ativos no projeto de iniciação científica realizado na Educação a Distância.

\section{FUNDAMENTAÇÃO TEÓRICA}

\subsection{Ensino a Distância e a Iniciação Científica}

O uso de novas tecnologias da informação e comunicação mostra-se como um grande diferencial da EaD. São computadores, webcam, chats, hiperlinks, vídeo-conferências, fóruns, internet, e-book, que tornam a modalidade de educação a distância muito mais dinâmica e atrativa. Entretanto, não podemos nos esquecer que todas as ferramentas que auxiliam o professor são tecnologias (PRADO; ROSA, 2008, p. 177).

Pensar em qualidade na $\mathrm{EaD}$, no ensino superior, leva à discussão da importância da pesquisa e extensão nessa modalidade de ensino. Umas das finalidades da educação 
superior é "incentivar o trabalho de pesquisa e investigação científica, visando o desenvolvimento da ciência e da tecnologia e da criação e difusão da cultura, e, desse modo, desenvolver o entendimento do homem e do meio em que vive" (BRASIL, 1996). À medida que eles ingressam em atividades de Iniciação Científica (IC), iniciam um processo de questionamento sistemático da realidade, que desencadeia no desenvolvimento de sua capacidade de investigação, inovação e intervenção do contexto social. Dessa forma, a atividade de pesquisa científica passa a integrar o cotidiano do acadêmico no intuito de desenvolver nele o espírito investigativo, que é de extrema importância para a construção do conhecimento científico, o qual esclarece muito dos problemas sociais e da natureza, colaborando para a transformação da sociedade (SALVI, 2017, p. 43).

Uma forma de ingressar o estudante na pesquisa e investigação é por meio da Iniciação Cientifica (IC), termo utilizado com a incumbência de introduzir o estudante na atividade de pesquisa e realizar a conexão da graduação com a pós-graduação. A iniciação científica é mais do que uma atividade que se pratica isoladamente. É uma atividade coletiva e também uma atitude crítica, reflexiva e investigatória diante daquilo que nos surpreende e causa admiração. Uma das finalidades da iniciação científica é aprimorar nosso pensamento e nos estimular a buscar soluções para os problemas do nosso cotidiano e do mundo do trabalho. Neste sentido, a iniciação científica é determinante para a vida acadêmica, para a prática da pesquisa e para a formação profissional (PEREIRA, 2016, p. 10).

Means et al. (2010) argumentam que o fato do estudante adotar práticas diferenciadas de ensino, proporciona melhor desempenho acadêmico, se comparado aos alunos, cuja aprendizagem está baseada em aspectos tradicionais. No entanto, Moré et al. (2010) salientam que o atendimento ao aluno é fator fundamental para um projeto na educação a distância ser bem-sucedido. Igualmente, a efetividade do acompanhamento ao discente, parte da definição dos papeis dos atores envolvidos no processo de ensino e aprendizagem, no qual docentes, tutores e coordenadores de cursos, possuem funções específicas para apoiar os alunos em sua caminhada acadêmica.

De acordo com Ebert et al. (2015), os alunos de cursos à distância, se identificam com a IC ofertada no currículo dos cursos, pois, conduz o acadêmico a participar do processo de construção do conhecimento. O aperfeiçoamento de novas tecnologias de informação e comunicação (TIC) tem colaborado para o processo de ensino e aprendizagem, inclusive na (IC) no EAD. Segundo Battini et al (2017), o acadêmico egresso na (IC) poderá, por meio do (AVA) construir saberes, desenvolver atividades, fazer questionamentos e participar de debates realizados, principalmente com o uso de 
ferramentas, tais como o chat semanal e fórum, com a participação de professores orientadores do projeto de pesquisa.

\subsection{A execução de um projeto de iniciação científica no EAD}

Os alunos que compuseram a amostra do presente artigo são participantes do projeto de Iniciação Científica na modalidade de ensino a distância, cujo objetivo é o de investigar práticas metodológicas utilizadas por professores da Educação Básica, principalmente do Ensino Fundamental II, para o ensino de conceitos da educação financeira. O tema "educação financeira" justifica-se devido ao fato de não serem raras as situações de adultos com dívidas ou pendências financeiras, sendo a Educação Básica essencial para a orientaçãodos estudantes sobre comolidar de forma racional com seus recursos, compreendendo questões relacionadas a parcelamentos, juros e descontos. Sendo assim considera-se que a prática da educação financeira adotada nas escolaspodem contribuir para a formação de um indivíduo com sensibilização maior acerca da estabilidade financeira.

Assim, esse projeto de pesquisa em andamento na Universidade Pítagoras Unopar na Modalidade de Ensino a Distância (Ead) buscacompreender as metodologias utilizadas para o ensino da educação financeira na Educação Básica, e justifica-se a partir do momento em que busca despertar a reflexão sobre um processo educativo articulado e compromissado com o tema, esperando-se obter retornos sociais de médio e longo prazo.

Os cursos de graduação envolvidos no projeto são: Administração, Ciências Contábeis, Ciências Econômicas, Gestão Financeira, e Licenciatura em Matemática por possuirem ligações com o tema de educação financeira, devido a abordagem emsuas grades curriculares por meio de disciplinas que contribuem com o debate em questão. Por tratarse de um tema que deve ser abordado de forma transvesal na Educação Básica, diversas são as contribuições que os alunos das diferentes áreas de atuação citadas poderão oferecer. A pesquisa em questão conta então com a participação de discentes de todos os cursos de graduação citados. Os discentes, inicialmente passam por um processo de capacitação (níveis 1 e 2 ) e, logo depois desenvolvem atividades de pesquisa sob a orientação e coordenação dos professores da Universidade.

\section{METODOLOGIA}

O presente artigo tem como objetivo analisar o perfil e a participação dos alunos ativos em um projeto de iniciação científica. Trata de um estudo de caso, o projeto de pesquisa 
- A educação financeira utilizada por professores na Educação Básica no Brasil - que serviu de base para o desenvolvimento de uma pesquisa exploratória (AAKER, KUMAR e DAY, 2004). Os dados secundários foram coletados no banco de dados da plataforma do projeto. As variáveis selecionadas estão relacionadas com o perfil sociodemográfico dos alunos bem como a localização dos polos de apoio, curso em que os alunos ativos estão matriculados, assim como indicadores de participação, como acesso à plataforma, realização do treinamento nível 1, bem como se o aluno já atuou em algum projeto de Iniciação Cientifica. $O$ projeto de pesquisa em estudo conta com um total de 241 alunos pesquisadores, e por simplificação optou-se pela realização de um censo. Para fins comparativos, também foram utilizados dados secundários coletados em artigos disponibilizados em meios digitais. Para proceder a análise os dados foram agrupados com o uso do software Excel.

\section{ANÁLISE DOS DADOS}

$\mathrm{Na}$ tentativa de análise do perfil dos alunos partipantes do PIC/Ead de Educação Financeira, foi utilizada a análise descritiva dos fatores sócio-demográfios dos mesmos. Quanto ao gênero dos participantes, a análise aponta que a maioria dos alunos ativos são do gênero feminino, resultado que vai de encontro com os dados do Censo da Educação a Distância (2016) realizado pela Assoiação Brasileira de Eduação a Distância (ABED), o qual aponta que $54,21 \%$ dos alunos de EAD das instituições privadas com fins lurativos são do gênero feminino. $O$ gráfico 1 mostra a participação por gênero, em percentuais.

GRÁFICO 1 - Gênero dos participantes

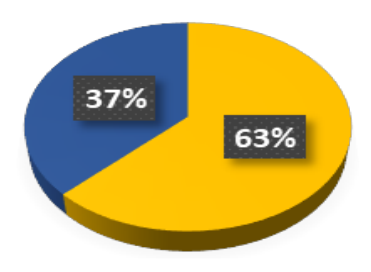

Fonte: Dados da pesquisa (2018)

Para constatação da idade dos participantes, foi utilizada a mesma distribuição de classes de faixa etária proposta pelo Censo EAD Brasil 2016, realizado pela Associação Brasileira de Educação a Distância (ABED). Segundo tal documento, a média de faixa etária dos alunos é maior para cursos totalmente a distância e na modalidade semipresencial, sendo que $34 \%$ dos alunos de cursos totalmente a distância possuem 
entre 31 - 40 anos. O gráfico 2 abaixo, aponta que a maioria dos alunos ativos no projeto, representam as faixas de 26 à 40 anos, sendo a média geral de idade de 31 anos, mantendo os mesmos padrões apresentados pelo Censo 2016.

GRÁFICO 2 - Idade dos participantes

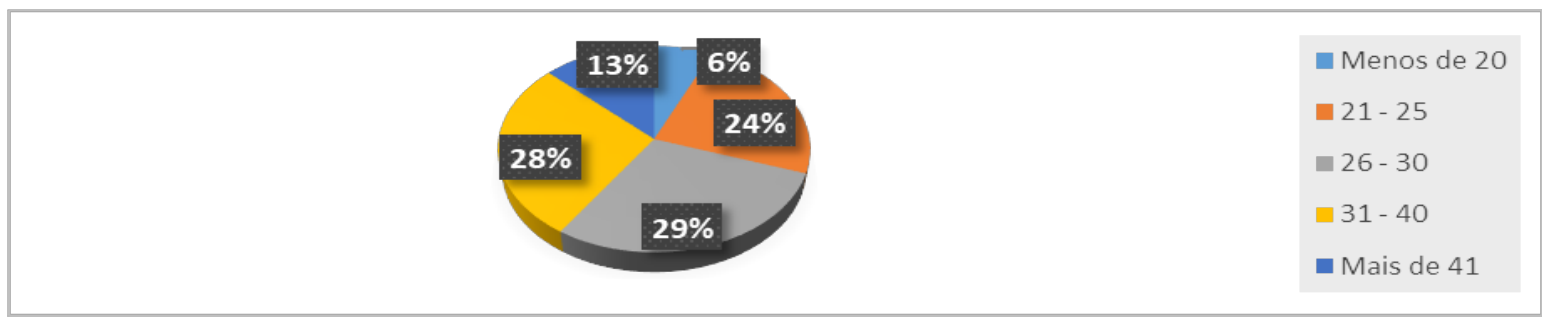

Fonte: Dados da pesquisa (2018)

Quanto aos cursos envolvidos na pesquisa, nota-se um maior envolvimento dos alunos do curso de Bacharelado em Ciências Contábeis, com 138 participantes, representrando $57 \%$ do universo de alunos, seguidos do curso de Administração, com $27 \%$ dos envolvidos. Nesta etapa do levantamento, notou-se o baixo envolvimento dos cursos de Ciências Econômicas, Gestão Financeira e Matemática com a Iniciação Científica, demonstrando haver a necessidade de maiores ações voltadas para tais cursos, em busca de maior captação de alunos. O gráfico 3 abaixo aponta em porcentagem, a participação por cursos envolvidos no projeto.

GRÁFICO 3 - Participação dos alunos por curso

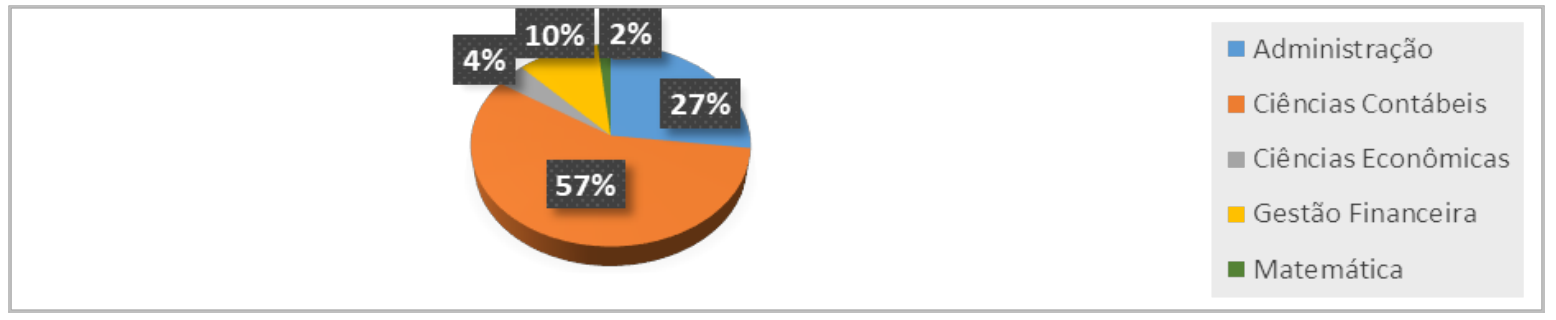

Fonte: Dados da pesquisa (2018)

Um fator de destaque no perfil dos alunos envolvidos com a iniciação científia na EAD é a diversidade regional. A eduação a distância tem possibilitado o acesso de jovens e adultos ao ensino de qualidade nas mais diferentes regiões do Brasil por meio de ferramentas digitais. Isso se estende também aos projetos de iniciação científica, e acaba por levar mais robustez e legitimidade aos resultados da pesquisa, que passam a ser representados pelas cinco regiões do país. A distribuição dos alunos participantes do PIC/Ead está representada na tabela 1 abaixo. 
TABELA 1 - Número de alunos participantes por região do Brasil

\begin{tabular}{ccc}
\hline Região & Núme ro de alunos \\
\hline Sul & 54 \\
Sudeste & 72 \\
Norte & 24 \\
Nordeste & 58 \\
Centro-oeste & 33 \\
Total & $\mathbf{2 4 1}$ \\
\hline
\end{tabular}

Fonte: Dados da pesquisa (2018)

Ainda com relação a distribuição regional, comparando o número de alunos participantes do projeto, com os números absolutos de alunos matriculados no EAD, apresentados pelo Censo EAD Brasil 2016, nota-se a mesma predominância das regiões Sul e Sudeste e uma surpreendente participação da região Nordeste, com 58 alunos envolvidos, em sua maioria, do estado da Bahia.

A participação de alunos também das regiões Norte e Centro-oeste, apontam que o projeto poderá contar com informações de todas as regiões brasileiras, contribuindo com uma coleta de dados diversificada, realizada em diferentes níveis educacionais e culturais de cada região, o que se apresenta muito positivo do ponto de vista de robustez dos dados coletados e dos resultados que a pesquisa alcançará. $\mathrm{O}$ gráfico 4 aponta a distribuição da porcentagem de alunos por região.

GRÁFICO 4 - Alunos por região

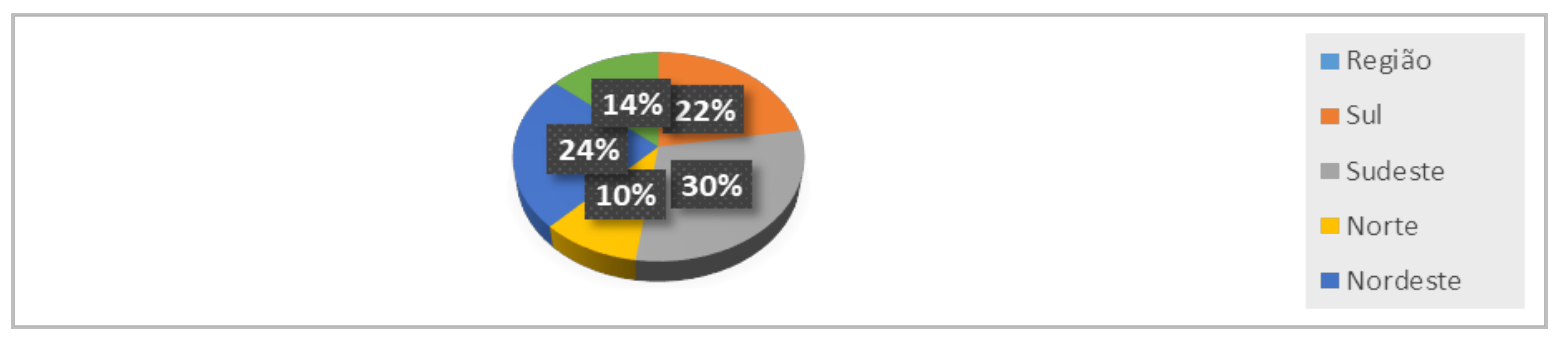

Fonte: Dados da pesquisa (2018)

Quanto a participação efetiva por parte dos alunos inscritos no projeto, foram analisados dados como número de acessos e finalização do treinamento nível 1, disponível no AVA Stricto. Cerca de $30 \%$ dos alunos ativos no projeto acessaram a plataforma mais de uma vez nos últimos 3 meses,conforme gráfico 5 . 
GRÁFICO 5 - \% de alunos que acessam a plataforma mais de uma vez em 3 meses

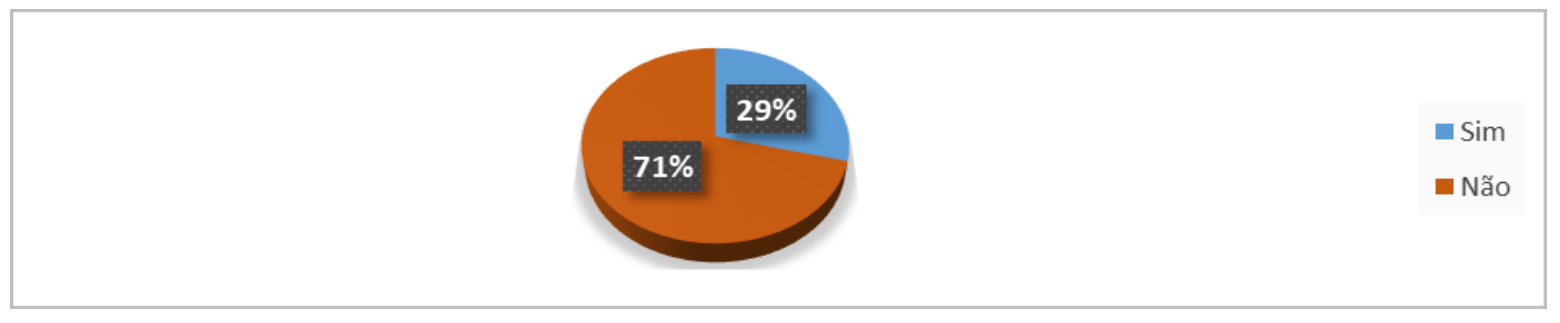

Fonte: Dados da pesquisa (2018)

O treinamento nível 1 foi disponibilizado a todos os alunos inscritos no projeto de pesquisa, sendo que tal módulo constitui-se como base de todas as atividades dos projetos vinculados ao Programa de Iniciação Científica no EaD (PIC EAD). Todo o treinamento foi disponibilizado diretamente via Ambiente AVA Stricto, estruturado por web aulas com os conteúdos programáticos de interesse para o desenvolvimento do projeto e crescimento profissional do aluno. Ate o presente momento, em 3 meses de atuação ativa do projeto, apenas $22 \%$ dos alunos finalizaram o treinamento nível 1 , conforme gráfico 6 abaixo.

GRÁFICO 6 - \% de alunos que finalizaram o treinamento nível 1

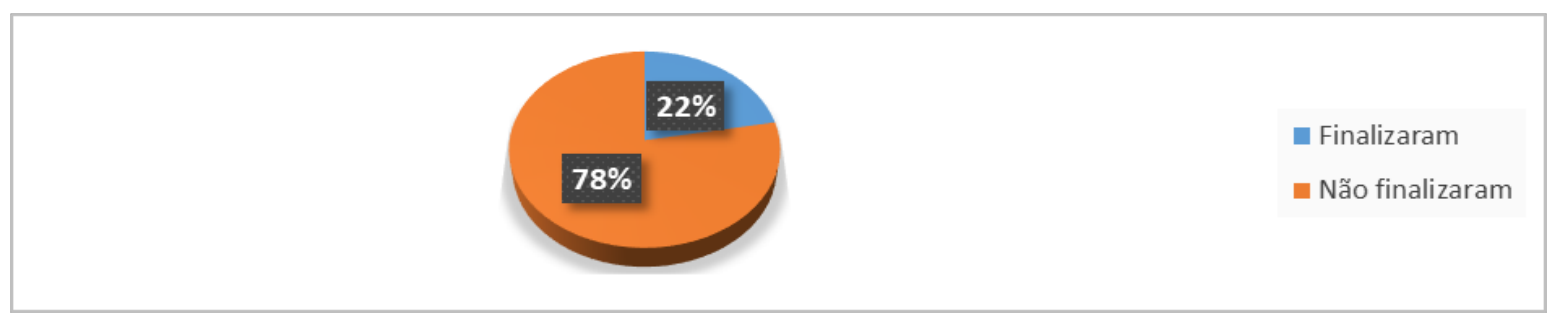

Fonte: Dados da pesquisa (2018)

Os números se justificam tambem por ser uma primeira experiência da maioria dos alunos, com projetos de iniciação científica. Conforme aponta o gráfico 7 abaixo, apenas $2 \%$ deles já participaram de iniciação científica em outras ocasiões.

GRÁFICO 7 - \% de alunos que já participaram de outros projetos de iniciação científica

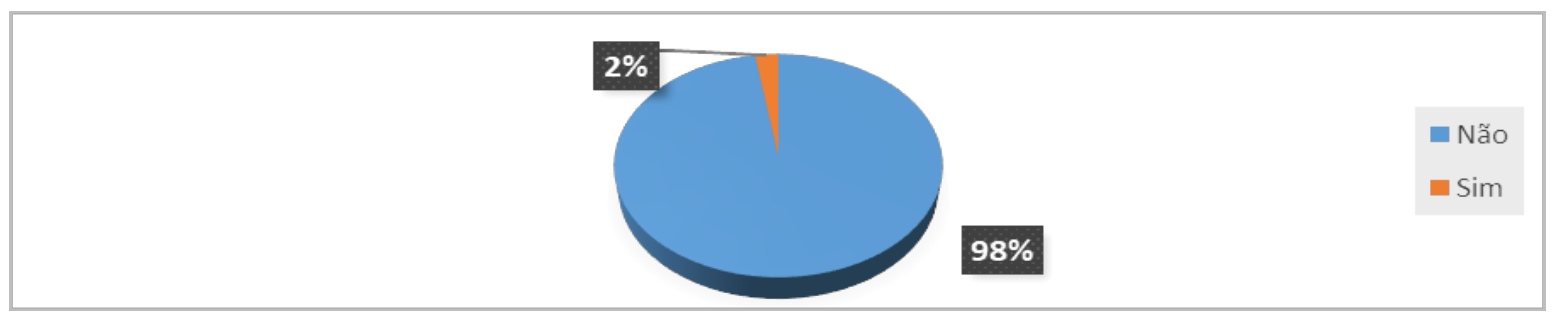


Fonte: Dados da pesquisa (2018)

Os dados apontam para a necessidade de maiores ações direcionadas por parte dos docentes e coordenadores, para que os alunos se sintam mais pertencentes ao projeto e se envolvam com mais afinco.

\section{CONSIDERAÇÕES FINAIS}

Para Salvi (2017), a formação de novos pesquisadores ainda é um grande desafio para as instituições de ensino, principalmente no EAD. Assim, é imprescindível que todas as IES desenvolvam processos de ensino à pesquisa e extensão, mediante o desenvolvimento da (IC) junto aos acadêmicos. Nesta perspectiva, o modelo acadêmico EAD que permita o apoio das ferramentas digitais para as atividades e práticas de (IC) tendem a ser mais eficazes. A IC possibilita a atuação dos alunos de graduação à desenvolverem projetos em diferentes áreas conhecimento, o que proporciona 0 envolvimento do discente com a atividade de pesquisa, em especial quando se tem tamanho alcance.

A partir dos dados analisados, observou-se uma necessidade de atuação mais efetiva dos professores do projeto junto aos alunos ativos, para que esses participem de forma mais notória e não evadam do projeto. Uma das ações que estão sendo realizadas envolvem telefonemas, e-mails e mensagens para os alunos, questionando as dificuldades encontradas por eles. A maioria dos alunos abordados nesta etapa, apontam ter interesse na continuidade do projeto mas apresentam dificuldades na realização das atividades. Neste sentido, docentes e coordenadores estão desenvolvendo estratégias de atuação para que se possa dar continuidade ao projeto com maior participação dos alunos inscritos.

\section{REFERÊNCIAS BIBLIOGRÁFICAS}

AAKER, D.; KUMAR, V.; DAY, G. S. Pesquisa de Marketing. São Paulo: Atlas, 2004

BATTINI. O.; FRANÇA. C.S.; REIS. S.R. A formação inicial de professores e a iniciação científica na modalidade a distância: uma experiência de construção. In: 13 - Educere. Congresso Nacional de Educação, 2017.

BRASIL. Lei de Diretrizes e Bases da Educação Nacional. Lei número 9394, 20 de dezembro de $1996 . \quad$ Disponível em: https://www2.senado.leg.br/bdsf/bitstream/handle/id/70320/65.pdf. Acesso em: 15 de 
maio de 2018.

EBERT. L.A.; NETTO.C.; TORRES, F,S. Iniciação científica na EAD: Como articular teoria e prática - estudo de caso da Uniasselvi. In: 21 CIAED - Congresso Internacional ABED de EaD, 2015. Anais do $20 \mathrm{CIAED} \mathrm{-} \mathrm{Congresso} \mathrm{Internacional} \mathrm{ABED}$ de EaD 2015.

PEREIRA, R. A. A importância da Iniciação Científica na formação acadêmica e profissional do aluno. Davar Polissêmica, v. 7, n. 1, 2016.

PRADO, E. C. do; ROSA, A. C. S. da. A interatividade na educação a distância: avanços e desafios. EccoS Revista Científica, São Paulo, v. 10, n. 1, p. 169-187, jan./jun. 2008.

MEANS, Barbara; TOYAMA, Yukie; MURPHY, Robert; BAKIA, Marianne; JONES, Karla. Evaluation of Evidence-Based Practices in Online Learning: A Meta Analysis and Review of Online Learning Studies. U.S. Department of Education. Center for Technology in Learning, 2010.

MORÉ, Rafael Pereira Ocampo; MORITZ, Gilberto de Oliveira; PEREIRA, Maurício Fernandes; MELO, Pedro Antônio. Modelo de gestão para educação a distância: 0 sistema de acompanhamento ao estudante - SAE. Revista de Administração e Inovação, São Paulo, v. 7, n. 2, p. 104-125, 2010.

SALVI, V.L. O processo de iniciação científica mediado pelas tecnologias na educação a distância. 2017. 134f.. Dissertação (Mestrado Acadêmico em Metodologias para o Ensino de Linguagens e suas Tecnologias) - Universidade Norte do Paraná, Londrina, 2017.

SILVA, P.C.D.; SHITSUKA, P.; PASCHOAL, P.A.G. Afetividade nas interações em AVA: um estudo sobre a interação na educação a distância. Revista Brasileira de Aprendizagem Aberta e a Distância, São Paulo, v.14, n.1, 2015 